\title{
Salt stress, its impacts on plants and the strategies plants are employing against it: A review
}

\author{
Zeenat Mushtaq ${ }^{1}$, Shahla Faizan ${ }^{1}$, Basit Gulzar²* \\ ${ }^{1}$ Environmental physiology laboratory Department of Botany Aligarh Muslim University, Aligarh 202002 (U.P), India. \\ ${ }^{2}$ Cellular differentiation and molecular genetics section, Department of Botany, Jamia Hamdard, New Delhi 110062, India.
}

\begin{tabular}{l}
\hline ARTICLE INFO \\
\hline Article history: \\
Received on: November 17, 2019 \\
Accepted on: March 04, 2020 \\
Available online: May 26, 2020 \\
\hline
\end{tabular}

Key words:

Salt stress, ion homeostasis, antioxidants, hormonal regulation

\begin{abstract}
Salt stress is said as the most harmful environmental issue affecting the agricultural productivity of many crops, with deleterious effect on plant growth, physiological and biochemical characteristics, vigour, and crop yields. Salt stress induced oxidative stress in plants by generating reactive oxygen species (ROS) that results impairment of cellular membranes, proteins of cells and organelles, especially of mitochondria, chloroplast, and peroxisomes and affects overall integrity of the cell. The various types of ROS are ${ }^{1} \mathrm{O}_{2}, \mathrm{H}_{2} \mathrm{O}_{2}, \mathrm{O}_{2}{ }^{--}$, and $\mathrm{OH}^{*}$. Salinity creates osmotic stress in plants that diminishes the root water absorption capacity and causes loss of water from the leaves that increases the accumulation of salts in salt stressed plants. However, plants show tolerance toward salt stress by involving large number of adaptations, for example, osmotic adjustment, ion homeostasis, hormonal regulation, antioxidant defense system, etc. Biosynthesis of plant growth hormones, such as cytokinins, abscisic acid, auxin, jasmonic acid, gibberellin, and ethylene play important role in amelioration of salt stress in plants by altering biochemical and physiological process plant tissues. Plants develop ion homeostasis in order to eliminate additional salt ions from cytosol by primary and secondary transport, maintains the balance of cytosolic concentration of $\mathrm{Na}^{+}$and $\mathrm{K}^{+}$ions, thus keeps the low concentration of $\mathrm{Na}^{+}$ions in cytosol as they are very harmful to cell when present in higher level. Plants develop antioxidant system constituting enzymatic components catalase, glutathione peroxidase, superoxide dismutase, ascorbate peroxidase, monodehydroascorbate reductase, and glutathione reductase and non-enzymatic components, such as glutathione, cysteine, tocopherols, and ascorbate that eliminate or neutralize ROS to cope with the oxidative stress by the antioxidant defense system and protect themselves against detrimental effects of ROS. In this review, we discuss on salt stress lead production of ROS, their formation, effects, and scavenging.
\end{abstract}

\section{INTRODUCTION}

Salinization of soil, a threat to the soil fertility, is increasing steadily in different parts of the world, especially in arid, semiarid, and areas which are heavily irrigated by salt containing water [1]. Soils that have an electrical conductivity of the saturation extract (ECc) of $4 \mathrm{dS} \mathrm{m}^{-1}$ or more are saline soils and soils with ECc's exceeding $15 \mathrm{dS} \mathrm{m}^{-1}$ are strongly saline [2]. It is expected that the increased salinization of arable land would result in 50\% land loss by the middle of twenty-first century [3]. Geological and hydrological factors, such as volcanic eruptions, rains, weathering

\footnotetext{
*Corresponding Author

Basit Gulzar, Cellular differentiation and molecular genetics section, Department of Botany, Jamia Hamdard, New Delhi 110062, India. E-mail: basit.gulzar786@gmail.co
}

of rocks are the natural factors that lead to the development of saline or sodic soils [4]. Water management, evapo-transpiration, and climatic factors may increase salinization and have key role in pedogenesis of saline soils in water scarce areas. Inundation of saline water, sea water brought by cyclones, and cyclical salts coming to coasts are main causes of salinization in coastal areas. Salinity may be anthropogenically induced due to deforestationg, over grassing, accumulation of water-borne and air-borne salts in soils, contamination with chemicals, etc. The amount of precipitation which decreases the salt concentration, evaporation which increases the same and other factors causing similar effects, determine the extent of salinity in a given area [5]. The basic structure of soil is disrupted with the increased deposition of sodium and other salts in higher concentrations that may result in lower soil porosity and aggravate the condition of reduced soil aeration and water conductance. Higher levels 
of soil salinity have detrimental effects on plant growth and development by inducing both hyperionic and hyperosmotic stress [6]. High salt depositions make the uptake of water and nutrients plants difficult by creating water potential deficit zone in the soil. Continued deposition of salts lead to a condition called physiological drought where by plants cannot take up the water present in the soil [7]. Osmotic stress caused by salinization and drought disrupts the ionic balance and overall homeostasis in the plant cell [8]. Different plants respond differently to the salinity depending on the genotype, adaptability, and other features of the plant. The differences in plant responses to the salinity are reflected in the plant growth and development. These differences determine the level of tolerance or the sensitivity of the plant to the salinity. Glycophytes, i.e., Salt sensitive plants for instance Zea mays, Oryza sativa, Phaseolus vulgaris, and Glycine max, cannot endure the higher levels of salt concentration, while halophytes for instance Medicago sativa, Atriplex amnicola, and Lepidium species can thrive well to some higher salinity levels. Salinity affects the physiological, biochemical, and molecular regime of plants ultimately leading to the reduction in productivity due to ionic imbalances, poor nutrient uptake, and redox state of cell and production of reactive oxygen species (ROS).

It is expected that the global warming due to the anthropogenic emission of trace gases, like $\mathrm{CO}_{2}$, would aggravate the problem of salt stress and desertification [9]. Disruption in coordination between light reaction and Calvin cycle in plants by combined effect of high irradiance and long-term salinity stress affects plant in various ways [10]. In ample $\mathrm{CO}_{2}$ concentration, the excessive electrons produced can react with $\mathrm{O}_{2}$ which may result the formation of harmful ROS, which when sufficiently accumulated cause photo inhibition. The phenomenon of photo inhibition is detrimental unless there is some protective strategy for quenching the free oxygen radicles or the absorption of excessive radiation [11]. The overproduction of ROS results in impairment of cellular membranes, proteins of cells and organelles, especially of mitochondria, chloroplast, and peroxisomes and affects overall integrity of the cell $[12,13]$.

The high salinity conditions are notorious for their detrimental effects on overall yield and the productivity (Table 1). Several strategies were developed and followed worldwide to counter the effects of salinity on the plant production. But unfortunately, to date, no successful method has been developed other than to develop salt tolerant plant varieties or species. Intensive studies are carried at different levels using different approaches, such as genomics, transcriptomics, and proteomics in order to understand the stress tolerance mechanisms and to develop plant genotypes that could endure the increasing salinity stress without compromising the yield.

\subsection{Generation of Various ROS due to Salinity}

Among all the stresses, salinity stress is one of the most deleterious and harmful stress in plant. Salt stress initially inhibits the water
Table 1: Yield loss of some crops at different levels of salt stress.

\begin{tabular}{lccc} 
Crops & Salt concentration & Yield loss & References \\
Peanuts & $4.7 \mathrm{dsm}^{-1}$ & $50 \%$ & {$[14]$} \\
Okra & $6.7 \mathrm{dsm}^{-1}$ & $90 \%$ & {$[15]$} \\
Rice & $7.0 \mathrm{dsm}^{-1}$ & $50 \%$ & {$[16]$} \\
Wheat & $13.0 \mathrm{dsm}^{-1}$ & $50 \%$ & {$[17]$} \\
Tomato & $1.5 \mathrm{dsm}^{-1}$ & $10 \%$ & {$[18]$} \\
Faba bean & $6.6 \mathrm{dsm}^{-1}$ & $50 \%$ & {$[19]$} \\
Chickpea & $3.8 \mathrm{dsm}^{-1}$ & $69 \%$ & {$[20]$} \\
Lentil & $3.1 \mathrm{dsm}^{-1}$ & $88 \%$ & {$[20]$} \\
Mungbean CV.(pusavishal) & $75 \mathrm{mM} \mathrm{NaCl}^{-1}$ & $68 \%$ & {$[21]$} \\
Mungbean Var 241/11 & $8 \mathrm{dsm}^{-1}$ & $62 \%$ & {$[22]$} \\
Pintobean CV-Talash & $12 \mathrm{dsm}^{-1}$ & $86 \%$ & {$[23]$} \\
Soybean & $7 \mathrm{dsm}^{-1}$ & $46 \%$ & {$[24]$} \\
Soybean & $6.3 \mathrm{dsm}^{-1}$ & $67 \%$ & {$[20]$} \\
\hline
\end{tabular}

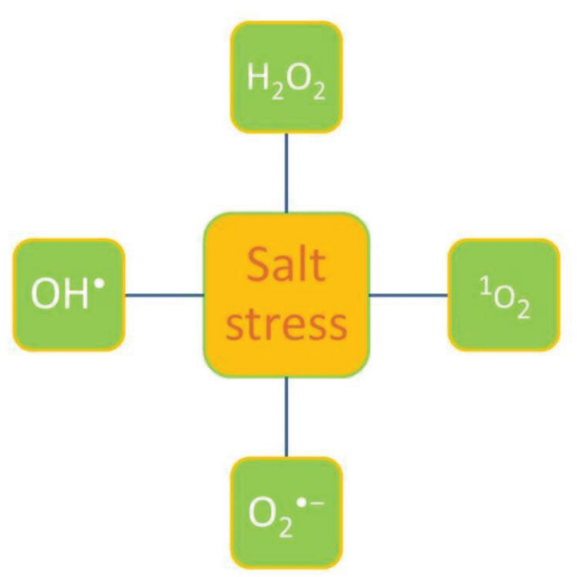

Figure 1: Generation of various ROS under salt stress.

absorbing capacity of plants, thus causes the osmotic stress. The salinity lead osmotic stress disturbs various physiological and biochemical processes, such as nutrient imbalance, generation of ROS, and membrane leakage. ROS are reactive molecules, free radicals derived from molecular oxygen (Fig. 1). Plant generally form ROS under normal conditions which are unable to cause any damage because these ROS are being scavenged by various types of antioxidant defense mechanisms. It has been estimated that less than $2 \%$ consumption of molecular oxygen by plants lead to the production of ROS in various cellular organelles, for example, mitochondria, chloroplast, peroxisomes, plasma membrane, cell wall, and endoplasmic reticulum (Fig. 2). ROS in plants plays both beneficial as well as harmful role depending up on their quantity. The various types of reactive oxygen are ${ }^{1} \mathrm{O}_{2}, \mathrm{H}_{2} \mathrm{O}_{2}, \mathrm{O}_{2}{ }^{--}$, and $\mathrm{OH}^{\circ}$. They play role of secondary messengers in cell organelles when present in less quantity, whereas at high concentration they are very deleterious and damage the proteins, genetic material, lipids, and other biomolecules, thus hinders the normal functioning of cells (Fig. 3). 


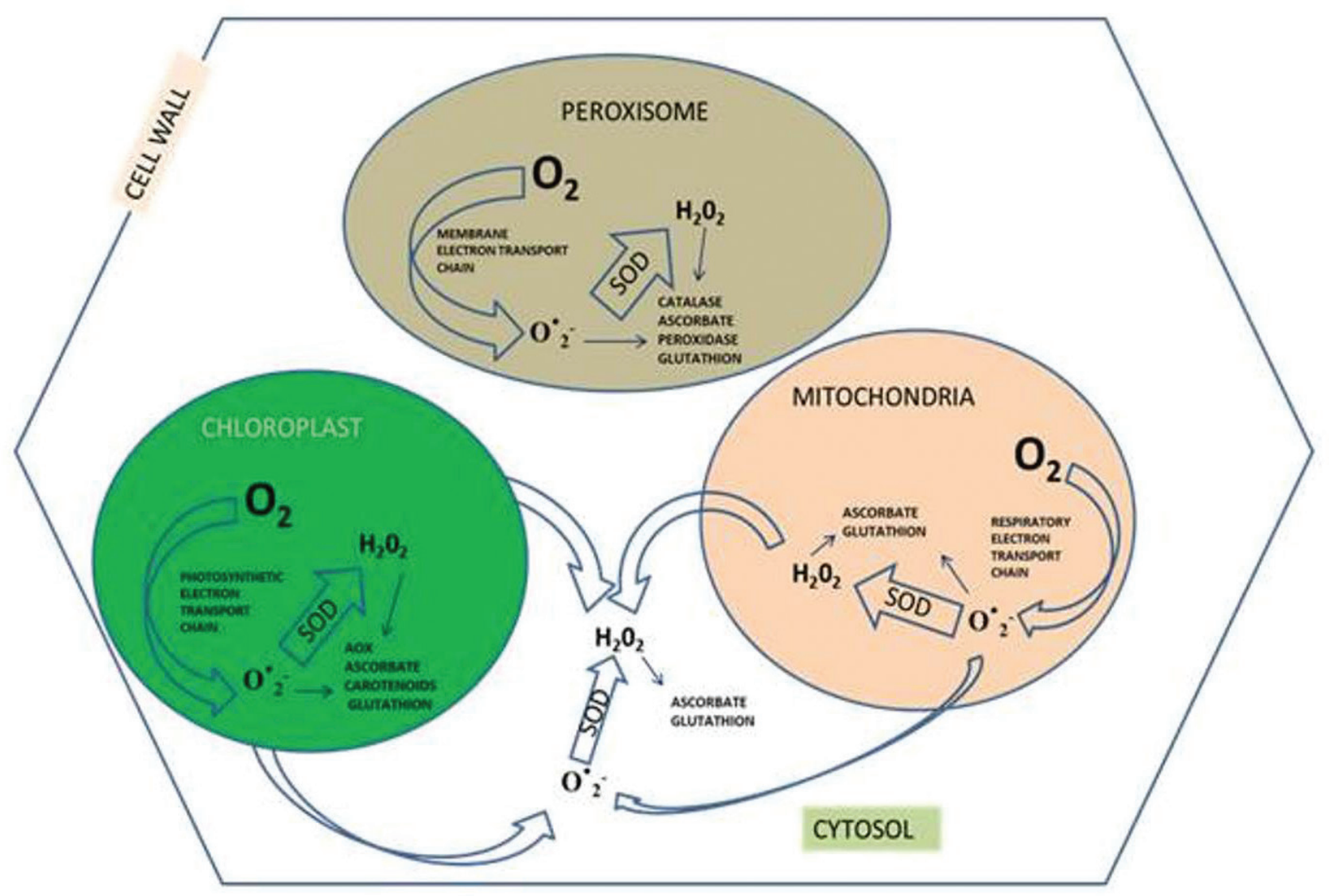

Figure 2: Some of the organelles where free radicles are produced and the mechanism of their generation.

\subsubsection{Superoxide radical $\left(\mathrm{O}_{2}^{--}\right)$}

Superoxide radicals are formed in photosystem I during non-cyclic electron transport chain. It is usually the first ROS formed during stress conditions and does not cause severe damage but under goes further reactions to generate other members of ROS.

\subsubsection{Singlet oxygen $\left({ }^{1} \mathrm{O}_{2}\right)$}

Singlet oxygen is a common ROS generated by the reaction of chlorophyll with molecular oxygen. Singlet oxygen damages both the photosystem I and photosystem II. This ROS has the ability to diffuse from one organelle to another and causes wide range of damage to genetic material, proteins, and lipids as well [24].

\subsubsection{Hydrogen peroxide $\left(\mathrm{H}_{2} \mathrm{O}_{2}\right)$}

Salt stress leads excessive production of hydrogen peroxide and can oxidize amino acids like methionine and cysteine, enzymes of Calvin cycle, also leads to programmed cell death [25]. It is less reactive than other types of ROS.

\subsubsection{Hydroxyl radical $(\mathrm{OH})$}

Among all the known ROS hydroxyl radical is most reactive and harmful ROS. It is generally formed by Fenton reaction between $\mathrm{H}_{2} \mathrm{O}_{2}$ and $\mathrm{O}_{2}^{-}$. It causes protein damage, lipid peroxidation and membrane disfunctioning.

\subsection{Damage of Lipids}

Lipids constitute the major portion of plasma membrane of cell and protect the cell from environmental stresses. Salt stress increases the levels of ROS and leads to lipid peroxidation. Lipid peroxidation due to salinity is very harmful, destroys the lipids by inducing the chain reaction and generates the lipid radicals which then damage other biomolecules. Salinity lead peroxidation of membrane lipids loses fluidity of membrane, elasticity, hinders normal functioning of cell, and also raptures the cell. Lipid peroxidation generates malondialdehyde (MDA) which is highly reactive carbonic compound and is considered as important biomarker of oxidative stress [26]. ROS attack the polyunsaturated fatty acids (PUFA) present in membrane, phospholipids are very much sensitive to these free radicals. These free radicals react with methylene groups of PUFA and form hydroperoxides, lipid peroxy radicals, and conjugated dienes [27].

$$
\begin{gathered}
\text { PUFA-H }+\mathrm{OH} \bullet \rightarrow \text { PUFA }^{\bullet} \text { (PUFA alkyl radical) }+\mathrm{H} 2 \mathrm{O} \\
\text { PUFA } \bullet+\text { O2 } \rightarrow \text { PUFA-OO` (Peroxyl radical) }
\end{gathered}
$$

\subsection{Proteins}

Salt stress lead production of ROS damage proteins in various ways. These species directly or indirectly affect the proteins. 


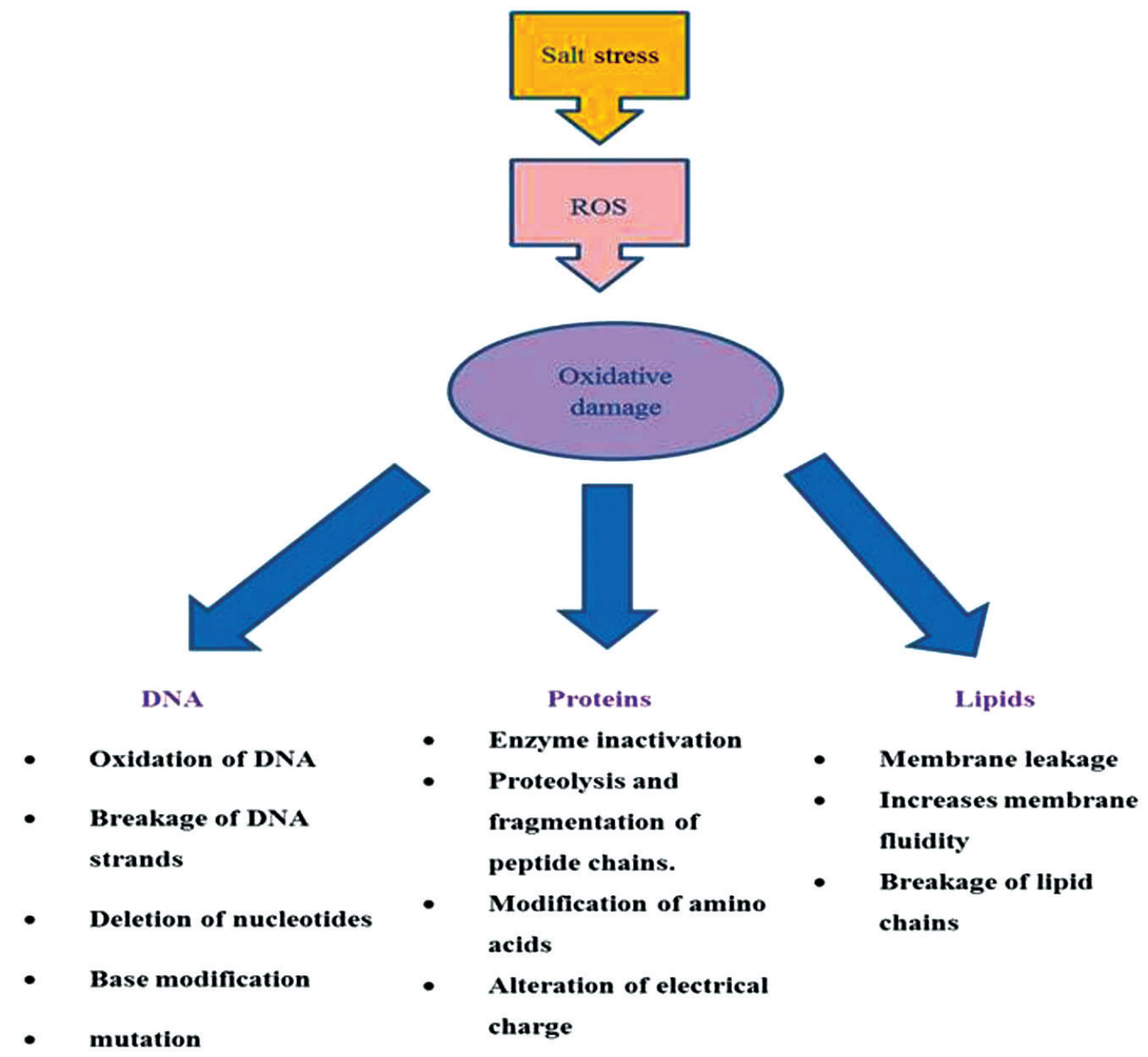

Figure 3: Oxidative damage induced due to ROS.

Formation of disulphide bonds, carbonylation, S-nitrosylation, and glutathionylation are the direct modifications of proteins caused by ROS. These modifications can be used as markers for assessing protein oxidation [28]. Indirect modifications of proteins via to ROS occur due to interaction of proteins with products of lipid peroxidation. Amino acids containing thiol and sulphur groups are very susceptible to ROS attack. Free radicals like ${ }^{1} \mathrm{O}_{2}$ and $\mathrm{OH}^{\cdot}$ are known to cause the depletion of thiol groups bound to protein.

The formation of disulphide bond due salt stress is one of the main mechanisms that affect the activity of large number of enzymes and translation factors in plants. Hydrogen peroxide induced generation of sulfenic acid that forms the disulphide bond between two cysteine molecules which changes the conformation of enzymes and their activity. Ronsein et al [29] put forth that ROS oxidizes tryptophan to highly unstable tryptophan hydroperoxides and immediately gets converted into kynurenine and N-formylkynurenine, which induces photoinhibition and regulates the process of photosynthesis in plants [30].

Superoxide radicals produced due to salinity lead oxidative stress, inactivate enzymes containing iron sulphur centers irreversibly, and oxidizes amino acids, such as Arg, Thr, Pro, His, and Lys [31]. According to Camejo [32], the oxidation and carboxylation of enzymes, such as glycine decarboxylase, pyruvate dehydrogenase, and acotinase, inhibit the Tricarboxylic acid cycle and suppress the energy status of cell.

\subsection{DNA}

Genetic material of plants both nuclear as well as organelle are attacked by ROS. Oxidative stress due salinity generates large quantity of ROS, which oxidizes the sugar residues, modifies nucleotide bases, breakage of DNA strands, cross links DNA and proteins etc. These radicals particularly hydroxyl radicals removes hydrogen atoms of sugar molecules of DNA and generates deoxyribose radicals, these radicals then breaks the deoxyribose backbone, strands of DNA and finally leads to mutation [33].

\section{Tolerance Mechanism}

Tolerance to salt stress is a complex process and involves large number of adaptations for example osmotic adjustment, ion homeostasis, hormonal regulation, antioxidant defense system etc. Mechanism of salt tolerance in plants is given below. 


\subsection{Osmotic Adjustment}

Osmotic adjustment is simply defined as the decrease in osmotic potential achieved by osmolyte accumulation in response to osmotic stress, and is regarded as a beneficial mechanism for salt adaptation in some crop species [34]. Enzymes, such as betaine aldehyde dehydrogenase, pyrroline-5-carboxylate reductase, and ornithine-d- aminotransferase play important role in osmotic adjustment in plants under salt stress. Plants are known to execute the processes of osmotic adjustment by up taking of inorganic ions and synthesis of organic solutes, such as proteins, polyols, sugars, and nitrogen containing compounds, such as amino acids, amines, and betaines. Under stressful conditions these solutes, also called as compatible solutes as they are not toxic to plants even at high concentration helps the plant to activate antioxidant defense mechanism [35], prevents denaturation of enzymes, and increases membrane stability. It was observed that in plants, for instance chickpea, soyabean show tolerance toward salinity, had higher concentration of compatible solutes, such as glycine betaine, proline, reducing sugars, and ascorbic acid than those plants which show sensitivity towards salinity [36]. Plants distribute the excessive sodium and chloride ions to vacuole and cytoplasm and stabilize the growth and other metabolic processes. Out of all known compatible solutes that help the plant to maintain the osmotic adjustment under salt stress, glycine betaine and proline constitute the major metabolites found in chickpea, durum wheat, Arabidopsis, soyabean, etc. Proline is a common osmolyte generally accumulates in large quantity in cytosol in response to salt stress in plants and helps in osmotic adjustment, stabilize subcellular structures, and scavenge free radicals. Glycine betaine is a water soluble, amphoteric ammonium containing osmolyte. It mitigates the salt stress by osmotic adjustment [37].

\subsection{Hormonal Regulation}

Salt stress rapidly reduces the growth, development, physiological, and biochemical processes but on the other hand, under stressful conditions, plants developed various adaptive strategies in order to withstand with environmental stresses. Hormonal regulation is one of the important strategies evolved by plants in order to cope up with salt stress. Hormones, such as cytokinins, abscisic acid (ABA), auxin, jasmonic acid, gibberellin, and ethylene play important role in amelioration of salt stress in plants.

Plant hormone cytokinins produced generally in root tips translocate via xylem to upper parts of plants where it plays role in various developmental processes, enhance tolerance toward salinity [38]. According to Pospisilova [39], cytokinins enable the stomatal closure and leaf senescence in plant under salt stress.

$\mathrm{ABA}$ is an essential hormone that plays an important role in amelioration of salt stress in plants. Salt stress quickly activates ABA synthetic genes ABA-aldehyde oxidase, epoxycarotenoid dioxygenase, zeaxanthin oxidase, and Mo containing sulfurase helps the plants to overcome salt led osmotic stress by accumulating osmoprotectants and closure of stomata [40]. It was observed that under salt stress increased concentration of ABA, up-regulates mitogen activated protein kinases gene family in rice plants which helps the plant to overcome the salt stress in this plant [41].
Auxin being an important hormone mainly generated in newly organs of plant plays important role in growth and development. Salt stress adversely affects its redistribution and hinders the growth and development particularly at seed germination and establishment. However, Akbari et al. [42] put forth that exogenous application of indole acetic acid to wheat seeds helps the plant to overcome the salt stress.

Jasmonic acid is well known signaling molecule as it is involved in various developmental processes and resistance towards different stresses in plants [43]. It was observed that salt tolerant crops accumulate high level of endogenous jasmonic acid than sensitive ones indicating that increased concentration of jasmonic acid could ameliorate the salt induced problems in plants [44].

Salt stress primarily affects root and shoot growth of plants, leaf formation, delays flowering period and other metabolic processes in plants. Hormone gibberelic acid was observed to play an important role in regulation of growth under salt stress mainly due to the DELLA protein (aspartate-glutamate-leucine-leucinealanine) family whose concentration gets increased when plant is under salt stress conditions. These proteins are directly involved in modulation of growth, flowering time, and plant hormone signaling pathways, thus enhances the salt stress tolerance in plants [45].

Various studies have observed that plant hormone ethylene signaling pathway mediates tolerance of salt stress in plants through the involvement of membrane receptors, nuclear transcription factors. It was observed that over expression of EIN3 due to ethylene signaling increased the tolerance of plants toward salt stress, increased the germination rate, and other germination developmental processes [46]. Besides, large number of ethylene mediated signaling pathways is involved in enhancement of salt tolerance in plants.

\subsection{Ion Homeostasis}

The maintenance of constant environment and control of ion concentrations across plant cell is called ion homeostasis. Control of ion concentration in the cytosol of cell under stressful conditions is important for regulation of metabolic enzymes, membrane potential maintenance and cell volume regulation [47]. Plants have the ability to eliminate additional salt ions from cytosol by primary and secondary transport in order to maintain the balance of cytosolic concentration of $\mathrm{Na}^{+}$and $\mathrm{K}^{+}$ions, thus keeps the low concentration of $\mathrm{Na}^{+}$ions in cytosol as they are very harmful to cell when present in higher level [48]. These ions are compartmentalized in cell vacuole via transporters, such as plasma membrane $\mathrm{H}^{+}$-ATPase, Vacuolar $\mathrm{H}^{+}$-ATPase, $\mathrm{H}^{+}$- Pyrophosphate, and $\mathrm{Ca}^{2+}$ ATPase. The main pathway involved in ion homeostasis and salt tolerance in plants is salt overly sensitive (SOS) stress signaling pathway [49]. This pathway consists of three proteins, SOS1, SOS2, and SOS3 and is sensor for calcium signal that turns on the machinery for $\mathrm{Na}+$ export and $\mathrm{K}+/ \mathrm{Na}+$ discrimination. SOS1 encodes $\mathrm{Na}+/ \mathrm{H}+$ antiporter and regulates the efflux of $\mathrm{Na}+$ at cellular level and controls the long distance transport of $\mathrm{Na}+$ ions from roots to shoots thus induces plant tolerance towards salinity. SOS2 encodes serine/ threonine kinase, and SOS3 is a myristoylation site containing protein and plays an important role in development of salt tolerance in plants [50]. 


\section{Antioxidant Defence System}

Plants have an antioxidant defense system through which they scavenge the highly ROS superoxide radicals, hydroxyl radicals, singlet oxygen, and hydrogen peroxide. This system consists of enzymes that are located at different cellular compartments and detoxifies the cell from toxic free radicals generated from salt stress. These enzymes include catalase (CAT), superoxide dismutase (SOD), ascorbate peroxidase (APX), glutathione reductase (GR), monodehydroascorbate reductase (MDHAR) and guaiacol peroxidase (GPX). Besides the enzymatic antioxidants certain non-enzymatic antioxidants like proline, flavonoids, tocopherols, ascorbic acid and carotenoids also plays important role in protection of cell from salt led oxidative stress (Table 2).

\subsection{Enzymatic Antioxidants}

Several enzymes play important role in the antioxidant defense system. These enzymes scavenge various reactive oxygen species in different cellular components. The important enzymatic antioxidants include Catalase, Superoxide dismutase, Ascorbate Peroxidase, Glutathione Reductase, Monodehydroascorbate reductase and Guaiacol Peroxidase.

\subsubsection{Catalase (CAT)}

CAT was said as first enzyme to be discovered that play role in defense against oxidative stress. CAT shows specificity to $\mathrm{H}_{2} \mathrm{O}_{2}$ and has very high turnover number and converts it into $\mathrm{H}_{2} \mathrm{O}$ and $\mathrm{O}_{2}$. The main site for the production of hydrogen peroxide radicals is peroxisomes; however, some recent studies show that this enzyme is also present in chloroplast, mitochondria, and cytosol $[63,64]$. CAT performs the Scavenging of $\mathrm{H}_{2} \mathrm{O}_{2}$ during $\beta$ oxidation of fatty acids and photorespiration in peroxisomes [65]. The unique feature of this enzyme is that it does not require any reducing agent.
Angiosperms that were studied till now contain three CAT genes, namely, CAT1, CAT2, and CAT3. Under stressed conditions, plant requires high-energy expenditure which is fulfilled by increasing its catabolic process due to which large concentration of $\mathrm{H}_{2} \mathrm{O}_{2}$ are generated, thus putting the plant in trouble. CAT overcomes this problem by the removal of $\mathrm{H}_{2} \mathrm{O}_{2}$ in an energy efficient way. CAT primarily mitigates the ROS generated during photorespiratory process and plants that lack their peroxisomal CAT are considered as the important tool for study of hydrogen peroxide signalling during different stress conditions [66]. Kibria et al. [67] observed that CAT activity significantly increases in rice plants grown under salt stress and provides tolerance to plants. Similar results were observed by Sobahan [68] in rice seedlings under salt stress.

$$
\mathrm{H}_{2} \mathrm{O}_{2} \rightarrow \mathrm{H}_{2} \mathrm{O}+(1 / 2) \mathrm{O}_{2}
$$

\subsubsection{Superoxide dismutase (SOD)}

SOD is an omnipresent metalloenzymes present almost in all aerobic organisms. SOD removes the superoxide radical $\left(\mathrm{O}_{2}{ }^{--}\right)$by converting it into oxygen and hydrogen peroxide molecules. This enzyme is said as first line of defense against oxidative damages. Based upon the metal ions used SOD is classified into three isozymes, viz, Fe-SOD found in chloroplast, Mn-SOD found in mitochondria, and $\mathrm{Cu} / \mathrm{Zn}$ - SOD present in cytosol, chloroplast and peroxisomes [69].

$$
\mathrm{O}_{2}^{--}+\mathrm{O}_{2}^{--}+2 \mathrm{H}+\rightarrow 2 \mathrm{H}_{2} \mathrm{O}_{2}+\mathrm{O}_{2}
$$

Under stressed conditions plants increase their SOD activity confirming that it increases the tolerance of plants toward environmental stresses [70]. Chawla et al. [71] identified that leaves of rice cultivars showed higher SOD activity and provides the plant tolerance toward salinity Elgawad et al. [72] also identified that SOD activity increases the salt tolerance of maize

\begin{tabular}{|c|c|c|c|}
\hline Enzymatic antioxidants & Cellular location & Function & References \\
\hline Catalase (CAT) & Mitochondria and Peroxisomes & Catalysis of $\mathrm{H}_{2} \mathrm{O}_{2}$ into $\mathrm{H}_{2} \mathrm{O}$ and $\mathrm{O}_{2}$. & [50] \\
\hline SOD & Mitochondria, Peroxisomes, Cytosol and Chloroplast. & Removal of $\mathrm{O}^{-}$by converting it into $\mathrm{H}_{2} \mathrm{O}$ and $\mathrm{O}_{2}$. & [51] \\
\hline APX & Mitochondria, Peroxisomes, Cytosol and Chloroplast. & Reduces $\mathrm{H}_{2} \mathrm{O}_{2}$ into $\mathrm{H}_{2} \mathrm{O}$ and DHA using (AA) as reducing agent. & [52] \\
\hline MDHAR & Mitochondria, Cytoplasm and Chloroplast. & Regenerates AA from MDHA, using NADPH as a reducing agent. & [53] \\
\hline GR & Mitochondria, Cytoplasm and Chloroplast. & $\begin{array}{l}\text { GR is a key enzyme of ASC-GSH cycle catalyzes the formation of a disulfide } \\
\text { bond in glutathione disulfide to maintain a high cellular GSH/GSSG ratio and } \\
\text { detoxifies } \mathrm{H}_{2} \mathrm{O}_{2} \text { generated by Mehler reaction in chloroplast. }\end{array}$ & [54] \\
\hline Dehydroascorbate reductase & Mitochondria, Cytoplasm and Chloroplast. & $\begin{array}{l}\text { Catalyzes the reduction of DHA to AsA using GSH as the reducing substrate } \\
\text { and maintains the redox state of plant cell. }\end{array}$ & [55] \\
\hline GPX & $\begin{array}{l}\text { Mitochondria, Cytoplasm, endoplasmic reticulum and } \\
\text { Chloroplast. }\end{array}$ & $\begin{array}{l}\text { Functions as effective quencher of intermediary forms of } \mathrm{O} 2 \text { and peroxy } \\
\text { radicals. }\end{array}$ & [56] \\
\hline Proline & Mitochondria, cytosol and chloroplast. & Scavenges $\mathrm{OH}^{\cdot}$ and ${ }^{1} \mathrm{O}_{2}$ and prevent harmful effects raised due to $\mathrm{LPO}$. & [57] \\
\hline Flavonoids & Cell Vacuoles & Scavenges $\mathrm{OH} ;{ }^{1}{ }^{\prime} \mathrm{O}_{2}$ and $\mathrm{H}_{2} \mathrm{O}_{2}$. & {$[58]$} \\
\hline (AA) & $\begin{array}{l}\text { Cytosol, Mitochondria, Peroxisome, Chloroplast, } \\
\text { Vacuole, and Apoplast. }\end{array}$ & $\begin{array}{l}\text { Protects membranes from oxidative damage and preserves the function of } \\
\text { metal-binding enzymes. }\end{array}$ & [59] \\
\hline Reduced Glutathione (GSH) & $\begin{array}{l}\text { Cytosol, ER, Mitochondria, Chloroplast, Vacuoles, } \\
\text { Peroxisomes and Apoplast. }\end{array}$ & $\begin{array}{l}\text { Scavenges } \mathrm{OH}^{\cdot},{ }^{1} \mathrm{O}_{2}, \mathrm{H}_{2} \mathrm{O}_{2} \text { and } \mathrm{O}^{-} \text {, also plays role in regeneration of ascorbic } \\
\text { acid to produce } \mathrm{GSSG} \text {, helps in chelation of heavy metal ions in plants. }\end{array}$ & {$[60]$} \\
\hline Carotenoids & $\begin{array}{l}\text { Found in both photosynthetic and non-photosynthetic } \\
\text { tissues of plants. }\end{array}$ & $\begin{array}{l}\text { Quenching of excess energy from PSI and PSII, inhibits lipid peroxidation, } \\
\text { scavenges }{ }^{\mathrm{O}} \mathrm{O}_{2} \text { and triplet Chlorophyll }\left(3 \mathrm{Ch}^{*}{ }^{*}\right) \text { molecules. }\end{array}$ & {$[61]$} \\
\hline$\alpha$-Tocopherol & Found only in green tissues of plants. & $\begin{array}{l}\text { Prevents chain propagation in lipid autooxidation, quenches excess energy, } \\
\text { maintains PSII structurally and functionally. }\end{array}$ & [62] \\
\hline
\end{tabular}

Table 2: Enzymatic and non-enzymatic antioxidants involved in detoxification of ROS along with important functions and their location in cell. 
seedlings under salt stress and helps the plant to overcome the oxidative damage caused due to excessive generation of ROS. In salt, stressed Cicer arietinum increase in activity of SOD was observed that helps the plant to with stand with salinity stress [73].

\subsubsection{Ascorbate Peroxidase (APX)}

APX is found in cytosol and chloroplast of the plant cell where it performs the same function as that of CAT. It is an integral constituent of Ascorbate-Glutathione (ASC-GSH) cycle. Unlike CAT APX uses Ascorbic acid (AA) as a reducing agent for catalysis or scavenging of hydrogen peroxide. In higher plants five distinct types of isoenzymes have been found in mitochondria, thylakoid, stroma, cytosol and peroxisomes based on sequence of amino acids.

The property of APX to be present in various cell organelles and its highest affinity for hydrogen peroxide radicals makes it proficient scavenger of $\mathrm{H}_{2} \mathrm{O}_{2}$ in plants under stressed environment and prevents the cell damage. Taibi et al. [74] studied that APX activity was increased in Phaseolus vulgaris due to salinity and provides tolerance to plants by detoxification of $\mathrm{H}_{2} \mathrm{O}_{2}$ under salinity. Similar results were reported by Demiral and Turkan [75] in rice cultivars under salt stress.

$$
\mathrm{H}_{2} \mathrm{O}_{2}+\mathrm{AA} \rightarrow 2 \mathrm{H}_{2} \mathrm{O}+\mathrm{DHA}
$$

\subsubsection{Glutathione Reductase (GR)}

GR is a member of flavoenzymes containing disulphide group. GR being NAD(P)H-dependent enzyme reduces Glutathione disulphide (GSSG) to GSH and balances cellular GSH/GSSG ratio. This enzyme is mainly found in chloroplast in high abundance while less in mitochondria and chloroplast. GSH reacts with ROS like hydroxyl radicals and superoxide radicals using nicotinamide adenine dinucleotide phosphate hydrogen (NADPH), thus prevents the cell from oxidative damage. An increase in GR activity in plants results in the accumulation of GSH and ultimately confers stress tolerance in plants. Various studies have demonstrated that abiotic stresses like salinity stress increases the GR activity in cowpea [76], French bean (Phaseolus vulgaris) [77], and Reaumuria soongorica (Pall.) [78]. Kumar et al. [79] observed in GR activity in Nerium oleander increases under salt stress and maintains the appropriate cellular redox state by catalyzing the reduction of $\mathrm{H}_{2} \mathrm{O}_{2}$ to water and oxygen coupled to ascorbate oxidation, and reduction of oxidized glutathione (GSSG) to GSH using NADPH as a cofactor.

$$
\mathrm{GSSG}+\mathrm{NADPH} \rightarrow 2 \mathrm{GSH}+\mathrm{NADP}^{+}
$$

\subsubsection{Monodehydroascorbate Reductase (MDHAR)}

MDHAR is a FAD enzyme, regenerates ascorbic acid from MDHA radicals by using NADPH as electron donor. This is only known enzyme that uses organic radical MDA as a substrate and reduces phenoxyl radicals [80]. It has various isoenzymes forms present in different organelles viz. chloroplast, mitochondria, cytosol and peroxisomes, where it scavenges $\mathrm{H}_{2} \mathrm{O}_{2}$ [81].
Eltayeb et al. [82] reported that overexpression of MDHAR in transgenic tobacco increased the tolerance against salt stresses by scavenging of harmful ROS and same report was observed in Acacia gerrardii by Hashem et al. [83] under salt stress.

$$
\mathrm{MDHA}+\mathrm{NADPH} \rightarrow \mathrm{AA}+\mathrm{NADP}^{+}
$$

\subsubsection{Guaiacol Peroxidase (GPX)}

GR is a heme-containing enzyme, excludes excessive hydrogen peroxide radicals from plant cells both during normal and stress conditions. It uses Guaiacol and pyrogallol as an electron donor for catalysis. GPX is said as stress enzyme and quenches peroxy radicals and other forms of oxygen radicals [84]. Enhanced GPX activities were more pronounced in salt-tolerant maize and provide the plant tolerance towards salinity [85].

\subsection{Non-enzymatic Antioxidants}

Nonenzymatic antioxidants also play an important role in defense of plants under environmental stresses by interacting with various components of cells and other metabolic processes thus enhance growth and development of plant. These include proline, glycine betaine, ascorbate, carotenoids and tocopherols.

\subsubsection{Proline}

Proline is a common osmolyte in plants and gets increased against various environmental stresses [86]. It is a multifunctional amino acid and has the signaling property by acting as plant growth regulator thus, influences various signaling processes. Proline is synthesized from glutamate and is a two-step process involving two enzymes $\Delta 1$-pyrroline-5-carboxylate synthetase and glutamate dehydrogenase. Under salt stress plants increase the endogenous level of proline, protects them from harmful effects of ROS. Increased proline content overcomes the negative effect of salinity by decreasing the accumulation of $\mathrm{Na}^{+}$and $\mathrm{Cl}^{-}$in plant cells [87]. Proline scavenges hydroxyl radicals $(\mathrm{OH} \bullet)$, superoxide radicals $\left({ }^{1} \mathrm{O}_{2}\right)$, reduces the damage raised due to lipid peroxidation and acts as a cytosolic $\mathrm{pH}$ buffer stabilizer for subcellular structures [88]. (Rahneshan et al. [89]) observed that moderate and high salinity induced a significant increase in the free proline content in leaves and roots of two pistachio cultivars, plays a protective role against salt stress in plants, same result was found by Karimi et al. [90] in P.vera.

\subsubsection{Glycine betaine}

Glycine betaine is an amphoteric amino acid, electrically neutral and highly soluble molecule. It is a non-toxic cellular osmolyte, increases the osmolarity in plant cells under stress conditions and mitigates the harmful effects of salt stress. It stabilizes the cellular proteins, protects the photosynthetic pigments from oxidative damage, and decreases the production of ROS and maintains osmotic adjustment of cells by distributing the sodium and chloride ions in cell vacuole and cytoplasm [91]. It was observed that increased level of glycine betaine overcomes redox imbalance, increases the tolerance towards salinity by maintaining membrane integrity, enzymatic activity and scavenging of harmful ROS [92]. 


\subsubsection{Ascorbate}

Ascorbate is one of the major antioxidant having low molecular weight present in cytoplasm of plants. Plants under salt stress increases the endogenous level of ascorbate, enhances plant growth, increases carbohydrate contents, mineral contents, phenols and plays an important role in various physiological processes like metabolism, differentiation and growth by donating the electrons to number of non-enzymatic reactions as well as reactions carried out by enzymes [93]. Synthesis of ascorbate in plants occurs via the uronic acid intermediates for example D-galacturonic acid [94]. Ascorbate protects the membrane by directly reacting with superoxide and hydrogen peroxide radicals, regenerates $\alpha$-tocopherol and maintains the activities of enzymes containing prosthetic transition metal ions [95]. It was observed that exogenous application of ascorbate mitigates the adverse effect of salinity stress in various plants like cherry tomato Plants [96], sugarcane [97] and promotes recovery from salt stress.

\subsubsection{Tocopherols}

There are four groups of tocopherols $\alpha, \beta, \gamma$, and $\delta$ representing lipophilic antioxidants. Under stress conditions particularly under salt stress tocopherols protects the plants from oxidative damage by scavenging harmful oxygen free radicals, lipid peroxy radicals and singlet oxygen in chloroplast, thus protects the basic structure and important functions of photosystem II B $[98,99]$. Among four different types of tocopherols $\alpha$-tocopherol having three methyl groups attached to its phenolic ring has maximum antioxidant activity [100]. Tocopherols are considered as effective free radical trap as they prevent the chain propagation in auto oxidation of lipids. It has been shown that accumulation of tocopherols especially $\alpha$-tocopherol induces tolerance to salinity in various plant species for example Medicage sativa [101].

\subsubsection{Carotenoids}

Carotenoids being important lipophilic antioxidants present in plants as well as microorganisms and are known to detoxify different types of ROS in plants [102]. Under stressed conditions carotenoids detoxifies singlet oxygen in order to control the oxidative damage and quenches triplet chlorophyll (3Chl*), excited form of chlorophyll $\left(\mathrm{Chl}^{*}\right)$ molecules, thus inhibits the formation of singlet oxygen species and finally protects important photosynthetic apparatus. Increased concentration of carotenoid content in sugarcane plants favors well adaptation under salt stress [103].

\section{CONCLUSION AND FUTURE PROSPECTUS}

The salinity stress severely affects the plant production by directly affecting the photosynthesis or indirectly by interfering with the plant nutrient absorption by roots, translocation of nutrients, or osmolytes, affecting the cellular membrane integrity due to overproduction of ROS, expenditure of extra energy in mitigating the negative effects of salinity stress, affecting the leaf morphology and disrupting the overall metabolism of the plant cells. Plants devise varied mechanisms to ameliorate the negative impacts of stressful conditions, important one being the antioxidant defense mechanism. The varied fields of plant research need to be integrated in order to gain the insightful knowledge at genetic, morphological and physiological level to tackle the harmful effects that salinity stress causes to the plants. Sophisticated, innovative molecular tools with the streamlined genetic engineering techniques, nanotechnology and the latest highly sensitive proteomic techniques like liquid chromatography mass spectroscopy (LC-MS) are very promising for developing the redressal mechanisms for the current salinity problems.

\section{CONFLICT OF INTEREST}

The authors declare that they do not have any conflicts of interest.

\section{FINANCIAL SUPPORT}

None.

\section{REFERENCES}

1. Giri B, Kapoor R, Mukerji, KG. Improved tolerance of Acacia nilotica to salt stress by arbuscular mycorrhiza, Glomus fasciculatum, may be partly related to elevated $\mathrm{K}^{+} / \mathrm{Na}^{+}$ratios in root and shoot tissues. Microb Ecol 2007;54:753-60.

2. FAO: Fact sheets: World Food Summit-November. FAO, Rome, Italy, 1996.

3. Wang WX, Vinocur B, Altman A. Plant responses to drought, salinity and extreme temperatures: towards genetic engineering for stress tolerance. Planta 2003;218:1-14.

4. Wanjogu SN, Muya EM, Gicheru PT Waruru BK. Soil degradation: management and rehabilitation in Kenya. Proceedings of the FAO/ ISCW expert consultation on management of degraded soil in Southern and Eastern Africa (MADS-SEA) 2nd Networking meeting, Pretoria, South Africa, PR102-113, 2001.

5. Mahajan S., Tuteja N. Cold, salinity and drought stresses: an overview. Arch Biochem Biophys 2005;444(2):139-58.

6. Porcel R, Aroca R, Ru1'z-Lozano JM. Salinity stress alleviation using arbuscular mycorrhizal fungi: a review. Agron Sustain Dev 2012;32:181-200.

7. Porcel R, Aroca R, Azcon R, Ruiz-Lozano JM. Regulation of cation transporter genes by the arbuscular mycorrhizal symbiosis in rice plants subjected to salinity suggests improved salt tolerance due to reduced $\mathrm{Na}^{+}$root to shoot distribution. Mycorrhiza 2016;26(7): 673-84.

8. Zhu JK. Cell signalling under salt, water and cold stresses. Curr Opin Plant Biol 2001;4(5):401-6.

9. Lavania, D, Siddiqui MH, Al-Whaibi MH, Singh AK, Kumar R, Grover A. Genetic approaches for breeding heat stress tolerance in faba bean (Vicia faba L.). Acta Physiol Plant Plant 2015;37:17-37.

10. Salazar-Parra C, Aguirreolea J, Sanchez-Diaz M, Irigoyen JJ, Morales F. Climate change (elevated CO2, elevated temperature and moderate drought) triggers the antioxidant enzymes response of grapevine cv. Tempranillo, avoiding oxidative damage. Physiol Plantarum 2012;144:99-110

11. García-Plazaola JI, Hernández A, Olano JM, Becerril JM. The operation of the lutein epoxide cycle correlates with energy dissipation. Funct Plant Biol 2003;30:319-24.

12. Mittler R. Oxidative stress, antioxidants and stress tolerance. Trends Plant Sci 2002;7(9):405-10.

13. Ahmad P, Sarwat M, Sharma S. Reactive oxygen species, antioxidants and signaling in plants. J Plant Biol 2008;51:167-73.

14. Shalhevet J, Reineger P, Shimshi D. Peanut response to uniform and non-uniform soil salinity. Agron J. 1969;61:384-87.

15. Minhas PS, Gupta RK. Using high salinity and SAR waters for crop production- Some Indian experiences In: Leith $\mathrm{H}$ and Al-Masoom AA (eds.). Towards the rational use of high salinity tolerant plants. Kluwer Academic Publishers, Amsterdam, Netherlands, pp 423-32, 1993.

16. Bresler E, McNeal BL, Carter DL. Saline and sodic soils: Principles Dynamics Modelling. Springer-Verlag, New York, NY, pp 236, 1982. 
17. Ayers RS, Westcot DW. Water quality for agriculture. FAO Irrigation and Drainage Paper 29, Rome, Italy. p 97, 1976.

18. Shalhevet J, Varon B. Effect of soil and water salinity on tomato growth. Plant Soil 1973;39:285-92.

19. Katerji N, van Hoorn JW, Hamdy A, Mastrorilli M. Salt tolerance classification of crops according to soil salinity and to water stress day index. Agr Water Manage 2004;3:99-109.

20. Van Hoorn JW, Katerji N, Hamdy A, Mastrorilli M. Effect of salinity on yield and nitrogen uptake of four grain legumes and on biological nitrogen contribution from the soil. Agr Water Manage 2001;51:87-98.

21. Schrawat N, Yadav M, Bhat KV, Sairam RK Jaiwal PK. Effects of salinity stress on mungbean genotypes [Vigna radiata L. wilezek] during consecutive summer and spring seasons. J Agr Sci 2015;60: 23-32.

22. Ahmad M. Effect of soil salinity on the yield and yield components of mungbean. Pak J Bot 2009;41:263-8.

23. Ghassemi-Golezani K, Taifeh-noori M, Oustan S, Moghaddam M, Seyyed-Rahmani S. Oil and protein accumulation in soybean grains under salinity stress. Not Scientia Biologicae. 2010;2:64-7.

24. Krieger-Liszkay A, Fufezan C, Trebst A. Singlet oxygen productionin photosystem II and related protection mechanism. Photosynth Res 2008;98:551-64.

25. Dat J, Vandenabeele S, Vranová E, Van Montagu M, Inzé D, Van Breusegem F. Dual action of the active oxygen species during plant stress responses. Cell Mol Life Sci 2000;57:779-95.

26. Kavas M, Baloğlu MC, Akça O, Köse FS, Gökçay D. Effect of drought stress on oxidative damage and antioxidant enzyme activity in melon seedlings. Turk J Biol 2013;37:491-8.

27. Smirnoff N. Antioxidant systems and plant response to the environment. In: Smirnoff N (ed.). Environment and plant metabolism, flexibility and acclimation, Bios Scientific Publishers, Oxford, UK, pp 217-43, 1995.

28. Moller IM, Jensen PE, Hansson A. Oxidative modifications to cellular components in plants. Ann Rev Plant Biol 2007;58:459-81.

29. Ronsein GE, Oliveira MC, Miyamoto S, Medeiros MH, Di Mascio P. Tryptophan oxidation by singlet molecular oxygen [1O2]: mechanistic studies using 180-labeled hydroperoxides, mass spectrometry, and light emission measurements. Chem Res Toxicol 2008;21:1271-83.

30. Kasson TM, Barry BA. Reactive oxygen and oxidative stress: $\mathrm{N}$-formyl kynurenine in photosystem II and non-photosynthetic proteins. Photosynth Res 2012;114:97-110.

31. Shacter E. Protein oxidative damage. Method Enzymol 2000;319: 428-36.

32. Camejo D, Jimenez A, Palma JM, Sevilla F. Proteomic identification of mitochondrial carbonylated proteins in two maturation stages of pepper fruits. Proteomics 2015;15:2634-42.

33. Halliwell B. Reactive species and antioxidants. Redox biology is a fundamental theme of aerobic life. Plant Physiolgy 2006;141:312-22.

34. Farooq M, Hussain M, Wakeel A, Siddique KHM. Salt stress in maize effects resistance mechanisms and seedling vigor as affected by seed priming in coarse rice. Can J Botany 2015;84:1196-202.

35. Bose J, Rodrigo-Moreno A, Shabala S. ROS homeostasis in halophytes in the context of salinity stress tolerance. J Exp Bot 2014;65:1241-57.

36. Dash MG, Panda SK. Salt stress induced changes in growth and enzymes activities in germinating phasselous mungo seeds. Biol Plantarum 2001;44:587-9.

37. Gadallah MAA. Effects of proline and glycinebetaine on Vicia faba responses to salt stress, Biol Plantarum 1999;2:249-57.

38. Javid MG, Sorooshzadeh A, Moradi F, Sanavy SAMM, Allahdadi I. The role of phytohormones in alleviating salt stress in crop plants. Aust J Crop Sci 2011; 5:726-34.

39. Pospisilova J, Vagner M, Malbeck J, Travniakova A, Batkova P. Interactions between abscisic acid and cytokinins during water stress and subsequent rehydration. Biol Plantarum. 2005;49:533-40.

40. Chinnusamy V, Zhu J, Zhu JK. Salt stress signaling and mechanisms of plant salt tolerance. Genet Eng 2006;27:141-77.
41. Rao KP, Richa T, Kumar K, Raghuram B, Sinha AK. In silico analysis reveals 75 members of mitogen-activated protein kinase kinase kinase gene family in rice. DNA Res 2010;17:139-53.

42. Akbari G, Sanavy SA, Yousefzadeh S. Effect of auxin and salt stress $(\mathrm{NaCl})$ on seed germination of wheat cultivars. Pak J Biol Sci 2007;10:2557-61.

43. Kazan K, Manners JM. JAZ repressors and the orchestration of phytohormone crosstalk. Trends Plant Sci 2012;17:22-31.

44. Kang D, Seo Y, Lee JD, Ishii R, Kim KU, Shin DH, et al. Jasmonic acid differentially affects growth, ion uptake and abscisic acid concentration in salt-tolerant and salt-sensitive rice cultivars. J Agronmy Crop Sci 2005;191:273-82.

45. Achard P, Cheng H, De Grauwe L, Decat J, Schoutteten H, Moritz $\mathrm{T}$, et al. Integration of plant responses to environmentally activated phytohormonal signals. Science 2006;311:91-4.

46. Wang YN, Wang T, Li KX, Li X. Genetic analysis of involvement of ETR1 in plant response to salt and osmotic stress. Plant Growth Regul. 2008;54:261-9.

47. Hasegawa PM. Sodium $\left(\mathrm{Na}^{+}\right)$homeostasis and salt tolerance of plants. Environ Exp Bot 2013;92:19-31.

48. Farooq M, Hussain M, Wakeel A, Siddique KHM. Salt stress in maize effects resistance mechanisms and seedling vigor as affected by seed priming in coarse rice. Can J Botany 2015;84:1196-202.

49. Zhu JK. Regulation of ion homeostasis under salt stress. Curr Opin Plant Biol 2003;6:441-5.

50. Quintero FJ, Martinez-Atienza J, Villalta I et al. Activation of the plasma membrane $\mathrm{Na} / \mathrm{H}$ antiporter salt-overly-sensitive 1 (SOS1) by phosphorylation of an auto-inhibitory C-terminal domain. Proc Natl Acad Sci USA 2011;108(6):2611-16.

51. Mallick N, Mohn FH. Reactive oxygen species: response of algal cells. J Plant Physiol 2000;2:183-93.

52. Scandalios JG. Oxygen stress and superoxide dismutases. Plant Physiol 1993;1:7-12.

53. Wang J, Zhang H, Allen RD. Overexpression of an Arabidopsis peroxisomal ascorbate peroxidase gene in tobacco increases protection against oxidative stress. Plant Cell Physiol 1999;7:725-32.

54. Ushimaru T, Maki Y, Sano S, Koshiba K, Asada K, Tsuji H. Induction of enzymes involved in the ascorbate dependent antioxidative system, namely, ascorbate peroxidase, monodehydroascorbate reductase and dehydroascorbate reductase, after exposure to air of rice seedlings germinated under water. Plant Cell Physiol 1997;5:541-9.

55. Yoshida S, Tamaoki M, Shikano T, Nakajima N, Ogawa D, Ioki M. et al. Cytosolic dehydroascorbate reductase is important for ozone tolerance in Arabidopsis thaliana. Plant Cell Physiol 2006;47(2): 304-8.

56. Chen Z, Gallie DR. Dehydroascorbate reductase affects leaf growth, development, and function. Plant Physiol 2006;142:775-87.

57. Van Gronsveld J, Clijsters H. Toxic effects of metals in plants and the chemical elements. In: Farago ME (ed.). Biochemistry, uptake, tolerance and toxicity, VCH Publishers, Weinheim, Germany, pp 150-77, 1994.

58. Yildiz M, Terz $\mathrm{H}$. Effect of $\mathrm{NaCl}$ stress on chlorophyll biosynthesis, proline, lipid peroxidation and antioxidative enzymes in leaves of salttolerant and salt sensitive barley cultivars. J Agr Sci 2013;19:79-88.

59. Fini A, Brunetti C, Di Ferdinando M, Ferrini F, Tattini M. Stress induced flavonoid biosynthesis and the antioxidant machinery of plants. Plant Signal Behav 2011;6:709-11.

60. Barnes J, Zheng Y, Lyons T. Plant resistance to ozone: the role of ascorbate. In: Omasa K, Saji H, Youssefian S, Kondo N (eds.). Air pollution and plant biotechnology - prospects for phytomonitoring and phytoremediation. Springer-Verlag, Tokyo, Japan, pp 235-52, 2002.

61. Roychoudhury A, Pradhan S, Chaudhuri B, Das K. Phytoremediation of toxic metals and the involvement of Brassica species. In: Anjum NA, Pereira ME, Ahmad I, Duarte AC, Umar S, Khan NA (eds.). Phytotechnologies: Remediation of environmental contaminants, CRC press; Taylor and Francis Group, Boca Raton, FL, pp 219-51, 2012. 
62. Li F, Vallabhaneni R, Yu J, Rocheford T, Wurtzel ET. The maize phytoene synthase gene family:over lapping roles for carotenogenesis in endosperm, photomorphogenesis, and thermal stress tolerance. Plant Physiol 2008;3:1334-46.

63. Ivanov BN, Khorobrykh S. Participation of photosynthetic electron transport in production and scavenging of reactive oxygen species. Antioxid Redox Sign 2003;1:43-53.

64. Mhamdi A, Queval G, Chaouch S, Vanderauwera S, Van Breusegem F, Noctor G. Catalase function in plants: a focus on Arabidopsis mutants as stress-mimic models. J Exp Bot 2010;61:4197-220.

65. Corpas FJ, Palma JM, Sandalio LM, Valderrama R, Barroso JB del $\mathrm{R}^{\prime}$ 10 LA. Peroxisomal xanthine oxidoreductase: characterization of the enzyme from pea (Pisum sativum L.) leaves. J Plant Physiol 2008;13:1319-30.

66. Kerchev PI, Waszczak C, Lewandowska A, Willems P, Shapiguzov A, Li Z, et al. Lack of Glycolate Oxidase 1, but not Glycolate Oxidase 2 , attenuates the photorespiratory phenotype of Catalase2-deficient Arabidopsis. Plant Physiol 2016;171:1704-19.

67. Kibria MD, Hossain M, Murata Y, Md Hoque A. Antioxidant defense mechanisms of salinity tolerance in rice genotypes. Rice Sci 2017;243:155-62.

68. Sobahan MA. Effect of exogenous proline and glycinebetaine on antioxidant enzymes activity in rice seedlings under salt stress. Albanian J Agr Sci 2018;17(4):211-8.

69. Mittler R. Oxidative stress, antioxidants and stress tolerance. Trends Plant Sci 2002;7:405-10.

70. Boguszewska D, Grudkowska M, Zagdañska B. Drought-responsive antioxidant enzymes in potato. Potato Res 2010;53:373-82.

71. Chawla S, Jain S, Jain V. Salinity induced oxidative stress and antioxidant system in salt-tolerant and salt-sensitive cultivars of rice (Oryza sativa L.). J Plant Biochem Biot 2013;22:27-34.

72. Elgawad HA, Zinta G, Hegab MM, Pandey R, Asard H, Abuelsoud W. High salinity induces different oxidative stress and antioxidant responses I maize seedlings organs. Front Plant Sci 2016;7:276.

73. Rasool S, Ahmad A, Siddiqi TO, Ahmad P. Changes in growth, lipid peroxidation and some key antioxidant enzymes in chickpea genotypes under salt stress. Acta Physiol Plant 2013;4:1039-50.

74. Taibi K, Fadhila taibi, Abderrahim LA, Ennajah A (2016) Effect of salt stress on growth, chlorophyll content, lipid peroxidation and antioxidant defense systems in (phaseolus vulgaris L.). S Afr J Bot 2016;105:306-12.

75. Demiral T, Turkan I. Comparative lipid peroxidation, antioxidant defense system and proline content in roots of two rice cultivars differing in salt tolerance. Environ Exp Bot 2005;53:247-57.

76. Contour-Ansel D, Torres-Franklin ML, Cruz H, de Carvalho M, D'arcy-Lameta A, Zuily-Fodil Y. Glutathione reductase in leaves of cowpea: cloning of two cDNAs, expression and enzymatic activity under progressive drought stress, desiccation and abscisic acid treatment. Ann Bot 2006;98:1279-87.

77. Nagesh Babu R, Devaraj VR. High temperature and salt stress response in French bean (Phaseolus vulgaris). Aust J Crop Sci 2008;2:40-8.

78. Bai J, Gong CM, Chen K, Kang HM, Wang G. Examination of antioxidative system's responses in the different phases of drought stress and during recovery in desert plant Reaumuria soongorica (Pall.) Maxim. J Plant Biol 2009;52:417-25.

79. Kumar D, Hassan MA, Naranjo MA, Agrawal V, Boscaiu M, Vicente O. Effects of salinity and drought on growth, ionic relations, compatible solutes and activation of antioxidant systems in oleander (Nerium oleander L.). PLoS One 2017;12(9):e0185017.

80. Sakihama Y, Mano J, Sano S, Asada K, Yamasaki H. Reduction of phenoxyl radicals mediated by monodehydroascorbate reductase. Biochem Biophys Res Commun 2000;3:949-95.

81. Mittler R. Oxidative stress, antioxidants and stress tolerance. Trends Plant Sci 2002;7:405-10.

82. Eltayeb AE, Kawano N, Badawi GH, Kaminaka H, Sanekata T, Shibahara T, et al. Overexpression of monodehydroascorbate reductase in transgenic tobacco confers enhanced tolerance to ozone, salt and polyethylene glycol stresses. Planta 2007;225:1255-64.

83. Hashem A, Abd Allah EF, Alqarawi AA, Al-Huqail AA, Shah MA Induction of osmoregulation and modulation of salt stress in Acacia gerrardii Benth. by Arbuscular Mycorrhizal Fungi and Bacillus subtilis (BERA 71). Hindawi Publishing Corporation BioMed Research International, p 11, 2016; Article ID 6294098.

84. Van Gronsveld J, Clijsters H. Toxic effects of metals in plants and the chemical elements. In: Farago ME (ed.). Biochemistry, uptake, tolerance and toxicity, VCH Publishers, Weinheim, Germany, pp 150-77, 1994

85. de Azevedo Neto AD, Tabosa JN. Salt stress in maize seedlings: II. Distribution of cationic macronutrients and its relation with sodium. Revista Brasileira de Engenhnaria Agricola e Ambiental 2000;4: 165-71.

86. Yildiz M, Terz H. Effect of $\mathrm{NaCl}$ stress on chlorophyll biosynthesis, proline, lipid peroxidation and antioxidative enzymes in leaves of salttolerant and salt sensitive barley cultivars. J Agr Sci 2013;19:79-88.

87. Kim GB, Nam YW. A novel $\Delta 1$-pyrroline-5-carboxylate synthetase gene of Medicago truncatula plays a predominant role in stressinduced proline accumulation during symbiotic nitrogen fixation. J Plant Physiol 2013;170:291-302.

88. Verbruggen N, Hermans C. Proline accumulation in plants: a review. Amino Acids 2008;35:753-9.

89. Rahneshan Z, Nasibi F, Moghadam AA. Effects of salinity stress on some growth, physiological, biochemical parameters and nutrients in two pistachio (Pistacia vera L.) rootstocks. J Plant Interact 2017;13(1):73-82.

90. Karimi HR, Maleki Kuhbanani R. Evaluation of inter-specific hybrid of $P$. atlantica $\times P$. vera $\mathrm{cv}$. 'Badami-Rize-Zarand' as pistachio rootstock to salinity stress according to some growth indices, echophysiological and biochemical parameter. J Stress Physiol Biochem 2014;10(3) $5-17$.

91. Makela P, Karkkainen J, Somersalo S. Effect of glycinebetaine on chloroplast ultrastructure, chlorophyll and protein content, and RuBPCO activities in tomato grown under drought or salinity. Biol Plantarum 2000;3:471-5

92. Kurepin LV, Ivanov AG, Zaman M, Pharis RP, Allakhverdiev SI, Hurry V, et al. Stress-related hormones and glycinebetaine interplay in protection of photosynthesis under abiotic stress conditions. Photosynth Res 2015;126:221-35.

93. Rawia Eid A, Taha LS, Ibrahiem SMM. Alleviation of adverse effects of salinity on growth, and chemical constituents of marigold plants by using glutathione and ascorbate. J Appl Sci Res 2011; 714-721.

94. Isherwood FA, Chen YT, Mapson LW. Synthesis of L-ascorbic acid in plants and animals. Biochem J 1954;1:1-15.

95. Noctor G, Foyer CH. Ascorbate and glutathione: keeping active oxygen under control. Annu Rev Plant Biol 1998;49:249-79.

96. Abdelgawad KF, El-Mogy MM, Mohamed MIA, Garchery C, Stevens RG. Increasing ascorbic acid content and salinity tolerance of cherry tomato plants by suppressed expression of the ascorbate oxidase gene. Agronomy 2019;9:51.

97. Munir, N, Aftab, F. Enhancement of salt tolerance in sugarcane by ascorbic acid pretreatment. Afr J Biotechnol 2011;10:18362-70.

98. Ivanov BN, Khorobrykh S. Participation of photosynthetic electron transport in production and scavenging of reactive oxygen species Antioxid Redox Sign 2003;1:43-53.

99. Diplock T, Machlin LJ, Packer L, Pryor WA. Vitamin E: biochemistry and health implications. Ann NY Acad Sci 1989;570:372-8.

100. De Pinto MC, De Gara L. Changes in the ascorbate metabolism of apoplastic and symplastic spaces are associated with cell differentiation. J Exp Bot 2004;408:2559-69.

101. Bafeel SO, Ibrahim MM. Antioxidants and accumulation of $\alpha$-tocopherol induce chilling tolerance in Medicago sativa. Int J Agric Biol 2008;6:593-8. 
102. Young J. The photo protective role of carotenoids in higher plants. Physiol Plantarum 1991;4:702-8.

103. Gomathi R, Rakkiyapan P. Comparative lipid peroxidation, leaf membrane thermostability and antioxidant system in four sugarcane genotypes differing in salt tolerance. Int J Plant Physi Biochem 2011;4:67-74.
How to cite this article:

Mushtaq Z, Faizan S, Gulzar B. Salt stress, its impacts

on plants and the strategies plants are employing against

it: a review. J Appl Biol Biotech 2020;8(03):081-091.

DOI: $10.7324 / \mathrm{JABB} .2020 .80315$ 